\title{
Quality Registers in Professional Health Care Educations; Knowledge Gaps and Proposed Actions
}

\author{
Annika M. M. Nordin'1, Torie Palm Ernsäter², Bo Bergman³ \\ 'School of Health Sciences, Jönköping University, annika.ma.nordin@lj.se \\ ${ }^{2}$ Swedish Society of Nursing, Torie.Ernsater@swenurse.se \\ ${ }^{3}$ Quality Sciences, Centre for Healthcare Improvement. Chalmers University of Technology, \\ bo.bergman@chalmers.se
}

\begin{abstract}
Background and purpose: The use of quality registers has increased rapidly in Sweden and they are identified as beneficial for health care competitiveness. A quality register is a structured gathering of patient information, to improve health care. However, the introduction of quality registers in health care organisations presupposes that employees know how to use them in quality improvement. Disconnections, or knowledge gaps, concerning quality registers hamper the possibilities to take advantage of them. Taking departure in professional health care educations, the purpose with the paper is to identify and explore knowledge gaps concerning quality registers. A second purpose is to propose actions to bridge the gaps.

Methodology/Approach: In 201250 semi-structured telephone interviews were completed and the material analysed in the search for knowledge gaps.

Results: Five knowledge gaps were found. Some professional health care educations teach improvement knowledge, but they have difficulties integrating quality registers as a resource in teaching. Quality registers do not sufficiently cooperate with professional health care educations and county councils do not generally include learning of quality registers in clinical placements/practicums.

Conclusion: Professional health care educations need forums where they can collaborate with others to jointly explore how learning of quality registers can be integrated. There are promising approaches.
\end{abstract}

Key words: quality registers, quality improvement, health care

\section{Introduction}

“... Health care will not realize its full potential unless change making becomes an intrinsic part of everyone's job, every day, in all parts of the system"

This is a powerful message by Batalden and Davidoff (2007, p. 2), that we all need to consider. As patient in health care systems we share the hope that the care we get is the best possible. Quality matters and it matters for us. Batalden and Davidoff (2007, p. 2) define quality improvement (QI) as "The combined and increasing efforts of everyone - health care professionals, patients and their families, researchers, payers, planners and educators - to make the changes that will lead to better patient outcomes (health), better system performance (care) and better professional development (learning)". This definition differs from many other definitions of QI in health care, mainly because it extends beyond solely identifying quality as an outcome (health, care and learning) - it also emphasises QI as a system. It points out that the system of QI in health care embraces actors on micro, meso and macro levels (Nelson, Batalden \& Godfrey, 2007). On a micro level patients, families, caregivers and change facilitators are examples of actors, whereas leaders, payers, planners and organisational support systems are examples on a meso level. Policymakers and health care educators are actors mainly found at the macro level.

To realise the full potential of the system of QI in health care, the actors need to identify shared goals and

Received: August 15, 2014; revised: October 6, 2014; accepted: October 28, 2014. An initial version of the paper was presented at $16^{\text {th }}$ Quality Management and Organizational Development Conference on Quality and Service Science ICQSS 2013, Portorož, Slovenia 
cooperate to achieve them. To support this, they need knowledge, tools, methods and structures that bring them closer together and support their shared communication. In this paper, one such shared structure - quality registers - is in focus.

From a global perspective Sweden has taken the lead in the development and use of quality registers (Rosén, Sjöberg $\&$ Åström, 2010). The increase of new quality registers can be described as a revolution; in the year 1989 eight quality registers were nationally accepted, by the year 2003 the number had grown to 42 , and by the year 2014, 81 had been accepted and another 24 registers had applied for national approval (Nulägesrapport 2014. Satsningen på kvalitetsregister, 2014). The Swedish government has, together with the Swedish Association of Local Authorities and Regions (SALAR), signed a five-year agreement (S2011/8471/FS) concerning shared responsibilities to develop, improve and implement quality registers.

The meta-message of this agreement is that quality registers are important and that they as a phenomenon are certain to stay in Swedish health care. However, the fact that quality registers is a part of the system of QI in health care presupposes that the actors in the system have knowledge about them, e.g. that health care organisations know how to use them in QI. Disconnections, or knowledge gaps concerning quality registers hampers the possibilities to take advantage of them.

A knowledge gap is in this paper defined as a gap between knowledge disciplines that needs to be bridged and the paper reports on a study on knowledge gaps concerning quality registers. The rationale for the study is that bridged knowledge gaps help actors in the system to take an increased advantage of quality registers, and hence, improve health care.

Health care educations train students to be future skilled employees, and therefore the paper takes departure in professional health care educations. The purpose is to identify and explore knowledge gaps concerning quality registers. The purpose is furthermore to propose actions to bridge these gaps.

The research questions are:

- $\quad$ Are there knowledge gaps concerning quality registers in professional health care educations?

- How can these knowledge gaps be bridged?

These questions have guided an empirical study including several actors in the Swedish system of QI in health care and the empirical material includes 50 interviews. In the next section the theoretical background for the paper is introduced and central concepts such as QI and quality registers are scrutinised. This is followed by a more thorough description of the method and design of the study. The results are compiled in section Results, and some of the results are transformed into an action plan for how knowledge gaps concerning quality registers can be bridged. This approach, using the findings to develop an action plan, indicates the influences of action research (Aagard Nielsen \& Svensson, 2006) in this study.

\subsection{Theoretical background}

\subsubsection{Quality registers}

The American surgeon Ernest Codman (1869-1940) is claimed to be one of the early proponents of quality registers (Neuhauser, 2002). In his work as a surgeon he noticed that the end result, the long term outcomes for treated patients, varied considerably and he realised that health care professionals needed to learn more about diagnostic and treatment errors to improve care. Based on the ambition to improve health care quality Codman started to systematically record outcomes of treated patients (Baumgart and Neuhauser, 2009; Neuhauser, 2002). This "end-result message" which Codman strongly advocated was at the time perceived as provocative, but is today the principal idea behind quality registers.

In Sweden the concept of quality register is defined as an automated and structured gathering of information about persons, with the specific purpose of systematic and continuous development of quality of health care. They are intended for research and play an important role in this respect. In a period of five years (2009 - 2013) approx. 1000 scientific articles based on data from quality registers were published (Nulägesrapport 2014. Satsningen på kvalitetsregister, 2014). Furthermore, the law declares that quality registers should enable comparisons on a regional or national level (SFS 2008:355).

The concept of quality registers is broad and includes registers with differing purposes. Common categories are registers for diagnoses and procedures (Larsson, Lawyer, Garellick, Lindahl and Lundström, 2012). The collected data in quality registers have different characters; some provide background information, others outcome measures or process data. Regardless of the kind of register, data need to be collected and a few registers are based on automatic data transfers from digital patient records. However, the majority of quality registers require manual recording. In Codman's time, the method of recording was the use of paper and pen, whereas computerised systems are the most common form today. Quality registers are based on the idea of systematic gathering of measures, with the purpose of improving the processes and treatments they cover. However, quality registers are databases, and an accumulation of measures alone is not an incentive for change. In terms of change, users at micro, meso and macro levels need knowledge of quality registers and how to use them in improvement efforts, that is, they need knowledge of QI.

Even though quality registers are important sources for research, and the numbers of articles based on quality registers increase there are only a few studies on how they are implemented or used by health care professionals. One recent study reports in how a quality register is introduced to a group of nurses (Rosengren, Höglund and Hedberg, 2012) and there are a few reports on how the use of quality registers increase adherence to national guidelines among health 
care professionals (Carlhed, Bojestig, Wallentin, Lindström, Peterson, Åberg and Lindahl, 2006; Peterson, Carlhed, Lindahl, Lindström, Åberg, Andersson-Gäre and Bojestig, 2007).

\subsubsection{Quality Improvement (QI)}

QI is a body of knowledge, a method and a philosophy for improvement. It's historical roots originate from Japan, where predecessors as Deming and Juran were pioneers. The tools and methods were first used in the industrial sector, but later spread into the service sector and health care (Bergman and Klefsjö, 2012). The introduction of QI in health care is even called revolutionary (Bevan, Robert, Bate, Maher and Wells, 2007; Ferlie and Shortell, 2001).

QI is a diverse field and in health care several schools, tools and methods are employed, e.g. Lean (Kollberg, Dahlgaard and Brehmer, 2007; Waring and Bishop, 2010), Continuos Quality Improvement (Counte and Meurer, 2001) and Six sigma (Pocha, 2010). However, the name of the schools, tools and methods does not determine the outcome, but that organisations have a holistic approach and are consistent in their values, methodologies and quality tools (Bergman and Klefsjö, 2012). A common fundamental aspect in all QI efforts is that they are expected to lead to improvements. To evaluate this data is necessary, which makes data collection fundamental in QI. Plentiful data enable for an indepth analysis of the current quality problem and underpin the on-going evaluation of the progress of the quality effort (Bergman and Klefsjö, 2012). Quality registers with their wide spread, is a natural source for various types of clinical data in health care.

There is a growing imperative to teach QI in health care educations and the subject is, or is suggested to be, included in curricula for several professional health care educations (Kyrkjebø and Hanestad, 2003; Headrick, Barton, Ogrinc, Strang, Aboumatar, Aud, Haidet, Lindell, Madigosky and Patterson, 2012; Wong, Etchells, Kuper, Levinson and Shojania, 2010).

However, to our knowledge there are no reports on how quality registers are included in teaching in professional health care educations, or how they are integrated in teaching of QI, why this paper provides with new and important insights in this area.

\section{Methods}

This is a qualitative interview study (Kvale and Brinkmann, 2009) based on 50 interviews carried out in the period October 2012 - December 2012. The sampling strategy is a combination of a purposive sampling and snowball sampling (Saunders, Lewis and Thornhill, 2009) and the National Network for Improvement Knowledge (NNIK) played a central role in the work of identifying potential respondents for the study. NNIK is an inter professional network of organisations and universities in the Swedish health care sector that volun- tarily collaborate to spread knowledge of QI among students (of all professions) and health care workers. The rationale for the collaboration is the conviction that theoretical and experiential aspects of QI are closely linked. Theories of QI need to be empirically tested and experienced by students in order to enhance their capacity to participate in QI project at their future work places, and it is valuable for employees in QI projects to anchor their experiences theoretically. NNIK is represented by universities that have integrated theories of QI in their curricula, and county councils and regions that actively support QI projects in their organisations. To promote approaches combining the use of quality registers and QI, NNIK in the year 2012 initiated a project that started with a study, which this paper reports on.

In a telephone conference, NNIK identified important actors in the system of QI in health care - eleven in total. These actors are briefly described in Table 1.

For each actor NNIK identified a number of potential respondents which received an invitation to participate in an interview. In the invitation the interview was described as a one-hour reflective discussion concerning QI and quality registers. If the invitation was accepted a telephone interview was conducted, whereas neglected or negatively answered invitations were left out. At the end of each interview the respondent was given the opportunity to suggest another potential respondent. The argument for this combined sampling strategy is that NNIK and the respondents together provide a rich overview of potential respondents for the study. Altogether, 50 interviews were carried out and in Table 1 the numbers in the third column show how many respondents from each actor that are included in the study. The primary data collection method was semi structured interviews (Yin, 2003). The interviews were designed to make gaps between the knowledge and resources the respondents had, and the knowledge and resources they would need in order to improve, visible. Therefore, the interview guide comprised open ended essay-questions to which the respondents responded by plentifully describing how they did, or wished to, support learning of QI and quality registers. To learn about the gaps the respondents also were asked to reflect over why the situation was at hand, how it could improve, and which collaborations that could be beneficial for improvement.

The interviews were not recorded. Instead rich hand notes were taken and to facilitate this a structured template inspired by SBAR was used. SBAR (Situation, Background, Assessment and Recommendation) is a standardised approach to communicate critical information. 
Table 1. Actors in the system of quality improvement and numbers of interviews

\begin{tabular}{|c|c|c|}
\hline Actors in the system & Organisations and respondents & No \\
\hline 1. Quality registers & $\begin{array}{l}\text { Leaders and coordinators of quality registers; a combination of the } \\
\text { largest quality registers and some smaller registers. }\end{array}$ & 8 \\
\hline 3. Organisations & $\begin{array}{l}\text { Leaders from a health care organisation; county councils, regions } \\
\text { and municipalities. }\end{array}$ & 7 \\
\hline 5. Nursing programs & Program managers or similar for nursing programs & 5 \\
\hline 6. Occupational therapist programs & Program managers or similar for occupational therapist programs & 2 \\
\hline 9. Other education types, e.g. master's programs & Program managers or similar & 3 \\
\hline 10. Steering committee of the project & Leaders both from NNIK and other organisations & 4 \\
\hline $\begin{array}{l}\text { 11. Preceptors of clinical practicums and student } \\
\text { training in health care organisations. }\end{array}$ & $\begin{array}{l}\text { Mainly preceptors of clinical practicums for doctors, nurses, } \\
\text { occupational therapists and physiotherapists }\end{array}$ & 13 \\
\hline
\end{tabular}

It was originally intended for the airline industry and military, but has in recent decades been adopted in fields as health care (Hohenhaus, Powell and Hohenhaus, 2006). In this study the structure of SBAR supported swift and structured hand notes. During the on-going interview the interviewer noted what the respondents said under the corresponding headings Situation (the respondent's role and relations to QI and quality registers), Background (respondent's way of working with QI and quality registers hitherto), Assessment (analysis and comparisons of results and needs) and Recommendations (actions, connections and collaborations to bridge gaps). SBAR is a minimum information tool (Cunningham, Weiland, Dijk van, Paddle, Shilkofski and Cunningham, 2012), but in this study the headings supported the interviewer to take notes in a structured way, even if the interview alternated between various issues and the researcher came with follow up questions. Beyond the fact that SBAR offered the researcher a functional structure for swift documentation it also simplified for the respondents. The interview transcriptions followed the SBAR headings and all interviews were reviewed and confirmed by the respondents. The clear and familiar structure is presumed to have facilitated the time-limited review process for the respondents and when respondents noticed misunderstandings or imprecision the documentation was improved in the suggested way.

Conventional content analysis was used to analyse the data (Graneheim and Lundman, 2004). First data under the headings Assessment and Recommendation was analysed in the search for knowledge gaps. This analysis was based on the manifest content, that is, what the respondents ex- plicitly discussed and mentioned as knowledge gaps in the interviews. These gaps were noted and sorted into groups. However, there were also indications of knowledge gaps under the headings Situation and Background. The cause for this is that the respondents had varying experiences and knowledge of QI and quality registers, and what one respondent could mentioned as a good idea worth trying (Recommendations) could by another respondent be confirmed as a working approach in their organisation under Background. The noted gaps were further compared and sorted and finally five knowledge gaps were identified.

The second research question of the paper, how the identified gaps can be bridged, is influenced by an action research approach (Aagard Nielsen and Svensson, 2006). Based on the identified knowledge gaps representatives from NNIK, the steering group for the project, the project management and some respondents from the study at meetings and telephone conferences analysed and discussed how the gaps could be bridged. Finally an action plan with four suggested actions was developed. The purpose with the action plan was to give guidance for the project initiated by NNIK. It points at improvement areas and the kind of actions that could bridge the gaps. However, due to the dynamic nature of the knowledge gaps and the actors in the system, the action plan is continuously developed.

The results of the study are presented in the next section. They are subdivided into two main categories: Knowledge gaps and Action plan to bridge knowledge gaps. For each category the findings are structured in bullet points. 


\section{Results}

\subsection{Knowledge gaps}

Knowledge gap 1. Teaching QI and quality registers in professional health care educations

Several professional health care educations have included QI in their curricula, and a few exhibit nascent approaches to teach knowledge of quality registers. However, they seem to have limited capacity to describe the theoretical and methodological connections between QI and quality registers (see theoretical background of this paper).

\section{Knowledge gap 2. Teaching quality registers and applied statistics}

Many professional health care educations miss the opportunity to include quality registers as a resource in the teaching of applied statistics. Large cohorts of employees work with quality registers continuously and they are often challenged to analyse large data sets. Profound analysis requires knowledge of e.g. applied statistics and applied statistics is a generic knowledge included in most curricula of professional health care educations. However, data from quality registers are normally not used in the teaching of applied statistics. Therefore professional health care educations miss the opportunity to illuminate where knowledge of applied statistics is probable to be used in practice, and students miss the chance of an early acquaintance with quality registers.

Knowledge gap 3. The notion of process in quality registers

The notion of process leads to confusion. In health care a process is a well-established notion for how one patient moves through the health care system as the treatment proceeds and with this narrow understanding the need for quality registers is limited. However, in QI the concept of process concerns aggregated outcome data. Without clarifications on the different levels of processes (single patients and groups of patients) it seems difficult for professional health care educations to explain the need for quality registers and subsequently, their connections to QI.

\section{Knowledge gap 4. Cumulative knowledge production in health care}

Professional health care educations miss out the opportunity to explain how quality registers contribute to the cumulative knowledge production in health care. They do not explain that employees registering in quality registers contribute to a modern continuous knowledge production of health care.

Knowledge gap 5. Learning about quality registers in clinical placements/practicums

Learning of quality registers is relatively absent in the clinical placements/practicums. In Sweden all professional health care educations include periods of clinical place- ments/practicums. The purpose is to offer students possibilities to learn and train important procedures and routines of their profession. However, even if quality registers nowadays are integrated in health care learning of quality registers is normally not integrated in clinical placements/practicums.

\subsection{Action plan to bridge knowledge gaps}

The action plan takes departure in the preceding knowledge gaps. The action plan is based on the belief that there is no single solution to all gaps. Instead the belief is that several smaller activities duplicated by many together construct the needed bridges. For this reason the improvement project aims to test small methodologies for how different actors can bridge the knowledge gaps.

Action 1. Quality register data available in professional health care educations

Quality registers need to develop accessible reports and IT-modules that can be used in the teaching of quality registers in professional health care educations. Thus, there is a need to develop more collaboration between quality registers and health care educations. In general, quality registers have not sufficiently identified health care educations as users of their registers and hence, health care educations have difficulties accessing quality register data.

\section{Action 2. Include learning of quality registers in teaching}

Professional health care educations need to develop methods to include learning of quality registers in the teaching. One ordinary method is to invite a representative from a quality register to present the register and to describe how the clinical outcomes are monitored. However, there are other methods as well. In a masters course e.g. students explored and examined an optional quality register in groups and presented and compared the quality registers at a final seminar. The course preceded courses in QI and individual essay writing which stimulated students to combine QI and quality registers in their essays. This kind of methods can be modified and adopted by other professional health care educations.

Action 3. Methods to integrate learning of quality registers in clinical placements/practicums

Professional health care educations and health care organisations need to develop methods to integrate learning of quality registers in clinical placements/practicums. Swedish professional health care educations include clinical placements/practicums and to organise and evaluate these practical learning moments representatives from educations and health care organisations have a long tradition of collaboration. 
However, time is scarce and they have limited resources to jointly reflect over how quality registers can be integrated in the clinical placements/practicums. Thus, one simple method is to invite representatives from educations and health care organisations to telephone conferences where ideas and experiences can be presented, compared and evaluated.

\section{Action 4. Develop generic knowledge of quality registers}

There is a need to develop publications and study materials that describe how quality registers, QI and applied statistics are connected. However, in this study quality registers claimed to lack the capacity to develop these tools and professional health care educations claimed not to have the required knowledge. Health care workers on the other hand have practical experience from this, but they lack the means to transform this into generic knowledge. One step in the right direction is a recent national publication, Ännu bättre vård (SALAR, 2013), that describes how applied statistics can be used to analyse complex aggregated outcome data for practitioners. Another step in the right direction is the current national action to write a basic study book about quality registers.

\section{Discussion}

Taking departure in professional health care educations, the purpose of the paper is to identify and explore knowledge gaps concerning quality registers, and the study has circled five gaps.

The first gap (Teaching QI and quality registers) concerns the fact that professional health care educations tend to have difficulties elucidating the relations between quality registers and QI. It is important to emphasise that promising approaches exist, but in general, there is a knowledge gap. The gap consists of missing links and explanations regarding how the knowledge disciplines are related and how they can be mutually advantageous.

This is even more apparent in the second knowledge gap (Teaching quality registers and applied statistics). Data collection is fundamental in QI and quality registers is a natural source for various types of clinical data but professional health care educations seem not sufficiently to highlight this. One explanation the respondents mention is that professional health care educations lack knowledge of quality registers and experience the access to register data as restricted.

The differing use of the notion process is in the third gap described as a barrier for the integration of quality register in professional health care educations. In health care a process is a well-established notion for the patient's flow through the system whereas a process in QI means aggregated outcome data. This kind of linguistic ambiguity can arise when a sector, in this case the health care sector, adopts expressions and concepts from another sector (the industrial sector). By circling the ambiguous meaning of process the study highlights consequences of adopting concepts from other sectors, whilst keeping the old perceptions intact.
The fourth knowledge gap (Cumulative knowledge production in health care) appears to be a promising way for professional health care educations to approach quality registers. Evidenced based medicine (EBM) is a well-established concept for knowledge production in health care and EBM requires research and practices to be based on extensive and high quality data. When health care workers register in quality registers they all participate in the data collection that will underpin this knowledge production. The collaborative and including aspects of quality registers were not mentioned by any respondents in the study, which indicates that they are overlooked.

The fifth gap (Learning about quality registers in clinical placements/practicums) points out that learning of quality registers normally is not integrated in clinical placements/ practicums. It has also been highlighted that there is a need for professional health care educations and health care organisations to collaborate around this, however, the locus of collaboration concerns the cross-section macro level (professional health care educations), meso level (organisational support systems) and microlevel (clinical supervisors and students), which makes the collaboration complex. For this reason it is helpful if a third party takes the initiative to coordinate the collaboration.

There are only a few scientific reports on how quality registers are implemented or used by health care professionals (Carlhed et al., 2006; Peterson et al., 2007; Rosengren et al., 2012). Quality registers, with their rich data, has a natural connection to QI and there is a growing imperative to teach QI in health care educations (Headrick et al., 2012; Kyrkjebø and Hanestad, 2003; Wong et al., 2010). However, to our knowledge there are no scientific reports on how quality registers are included in professional health care educations, or how they are integrated in teaching of QI. Therefore the paper provides with important insights.

The paper identifies knowledge gaps that have significance for the integration of quality registers in teaching and it points out actions to bridge the gaps. A common denominator of the proposed actions is the need for actors in the system of QI in health care to collaborate on micro, meso and macro levels, which corresponds with the definition of QI by Batalden and Davidoff. They point out that QI is more than its outcome; it does also embrace everyone's connected and combined efforts (e.g collaborations), to improve the system (Batalden and Davidoff, 2007).

This study reveals that the efforts are not sufficiently connected and combined, which means that the system is fragile. To build a more robust system the arrangement of forums where actors can collaborate around quality registers and it's integration in professional health care educations is needed. 
In this study the choice of method has been advantageous for reasons that were not apparent when it was chosen. Several respondents claimed never to have problematised the theoretical and practical connections between quality registers and QI and the interviews offered time to reflect over this. Many respondents did initially not recognise that they had approaches for quality registers; however, in the interviews they discovered this. Some respondents decided directly to develop their ideas further. For example, some professional health care educations included quality registers in the clinical placements/practicums, some health care organisations decided to invite students to internal quality conferences and some quality registers realised they needed to collaborate with professional health care educations. In this way the interviews sometimes functioned as an intervention. Another aspect of the method was that the interviewer, using the SBAR structure, systematically documented the ideas and actions developed in the interviews, and related to them in the forthcoming interviews. In this way the method supported a feed forward approach.

\section{Conclusions}

Taking departure in professional health care educations, this study has identified five knowledge gaps concerning quality registers. Professional health care educations tend to have difficulties elucidating the relations between quality registers, QI and applied statistics. The gap consists of missing explanations of how the knowledge disciplines are interrelated and dependent on each other. To bridge the gaps collaborations at micro, meso and macro levels are suggested. The action plan highlights the need for different forums where actors can connect and combine their efforts, which is in line with the definition of QI by Batalden and Davidoff (2007).

One limitation with the study is that no reminders were sent to the first set of proposed respondents. The rationale for this is that the study period was limited and that the identified and proposed respondents only were examples of specific actors. Instead of reminders, participating respondents were given the opportunity to suggest a potential respondent. With this combined sampling strategy the study in a short period of time included 50 respondents, representing all actors. Another limitation could at first glance be that only eight quality registers are included in the study. However, four register centres are also included. These centres have service contracts with approximately 30 quality registers, which means that they together represent large proportions of Sweden's quality registers.

This paper has implications for theory. To our knowledge there are no scientific reports on how quality registers are included in teaching in professional health care educations, or how they are integrated in teaching of QI. This paper provides with first insights in this area and it is important to study what different actors do to bridge the gaps, and how it works. One important aspect to study is how students' understandings and perceptions of their becoming work is influenced by learnings of QI and quality registers.

However, the paper does also have implications for practice. Sweden has a leading position in the use and development of quality registers (Rosén et al., 2010) and the paper offers early insights for other countries with the same ambition. Professional health care educations need to take the knowledge gaps into account and to consider which actions that are beneficial for their students. They can also collaborate to organise forums, where actors from different parts of the system of QI in health care can connect and combine their efforts. In Sweden NNIK has applied for funding to support efforts of this character and there is an initiative to write a basic study book about quality registers, which in turn can be useful in teaching of quality registers.

\section{Acknowledgement}

The authors thank NNIK (Nationell Plattform för förbättringskunskap) for its support with this study. NNIK initiated the study and the improvement project based on the action plan. NNIK has provided with valuable contacts to potential respondents, which facilitated the interview process. NNIK is a network organisation with representatives from health care organisations, universities and societies for health care professions. NNIK offers a platform where actors in the Swedish system for QI in health care can share experiences and learn together. The yearly summer dialogue (Sommardialogen) and the webpage (www.forbattringskunskap.se) are important meetings points for NNIK.

\section{Literature}

Aagard Nielsen, K. A., \& Svensson, L. (2006). Action research and interaction research:beyond practice and theory. Maastricht: Shaker Publishing.

Batalden, P. B., \& Davidoff, F. (2007). What is quality improvement and how can it transform health care? Quality and Safety in Health Care, 16(1), 2-3, http:// dx.doi.org/10.1136/qshc.2006.022046

Baumgart, A., \& Neuhauser, D. (2009). Frank and Lillian Gilbrecht; scientific management in the operating room. Quality and Safety in Health Care, 18(5), 413-415, http://dx.doi.org/10.1136/qshc.2009.032409

Bergman, B., \& Klefsjö, B. (2012). Kvalitet från behov till användning. (5th ed.) Lund: Studentlitteratur.

Bevan, H., Robert, G., Bate, P., Maher, L., \& Wells, J. (2007). Using a design approach to assist large scale organizational change: 10 high impact changes to improve the National health services in England. The Journal of Applied Behavioral Science,43(1), 135-152, http://dx.doi.org/10.1177/0021886306297062

Carlhed, R., Bojestig, M., Wallentin, L., Lindström, G., Peterson, A., Åberg, C., \& Lindahl, B.(2006). 
Improved adherence to Swedish national guidelines for acute myocardial infarction: the Quality Improvement in Coronary Care (QUICC) study. American Heart Journal, 152(6), 1175-1181, http://dx.doi.org/10.1016/j. ahj.2006.07.028

Counte, M. A., \& Meurer, S. (2001). Issues in the assessment of continuous quality improvement implementation in health care organizations. International Journal for Quality in Health Care, 13(3), 197-207, http://dx.doi. org/10.1093/intqhe/13.3.197

Cunningham, N. J., Weiland, T. J., Dijk van, J., Paddle, P., Shilkofski, N., \& Cunningham, N. Y. (2012). Telephone referrals by junior doctors: a randomized controlled trial assessing the impact of SBAR in a simulated setting. Postgraduate Medical Journal, 88(1045), 619-626, http://dx.doi.org/10.1136/postgradmedj-2011-130719

Ferlie, E. B., \& Shortell, S. M. (2001). Improving the quality of health care in the United Kingdom and the United States: a framework for change. Milbank Quarterly, 79(2), 281-315, http://dx.doi.org/10.1111/14680009.00206

Graneheim, U. H., \& Lundman, B. (2004). Qualitative content analysis in nursing research: concepts, procedures and measures to achieve trustworthiness. Nurse Education Today, 24(2), 105-112, http://dx.doi. org/10.1016/j.nedt.2003.10.001

Headrick, L. A., Barton, A. J., Ogrinc, G., Strang, C., Aboumatar, H. J., Aud, M. A., Haidet,P., Lindell, D., Madigosky, W. S., \& Patterson, J. E. (2012). Results of an effort to integrate quality and safety into medical and nursing school curricula and foster joint learning. Health Affairs, 31(12), 2669-2680, http://dx.doi.org/10.1377/ hlthaff.2011.0121

Hohenhaus, S., Powell, S., \& Hohenhaus, J. T. (2006). Enhancing Patient Safety During Hand Offs: Standardized communication and teamwork using the "SBAR" method. The American Journal of Nursing, 106(8), 71A-72B.

Kollberg, B., Dahlgaard, J. J., \& Brehmer, P. O. (2007). Measuring lean initiatives in health care services: issues and findings. International Journal of Productivity and Performance Management, 1(56), 7-24, http://dx.doi. org/10.1108/17410400710717064

Kyrkjebø, J. M., \& Hanestad, B. R. (2003). Personal improvement project in nursing education: learning methods and tools for continuous quality improvement in nursing practice. Journal of Advanced Nursing, 41(4), 8898, http://dx.doi.org/10.1046/j.1365-2648.2003.02510.x

Kvale, S., \& Brinkmann, S. E. (2009). Den kvalitativa forskningsintervjun. Lund: Studentlitteratur.

Larsson, S., Lawyer, P., Garellick, G., Lindahl, B., \& Lundström, M. (2012). Use of 13 disease registries in 5 countries demonstrates the potential to use outcome data to improve health care's value. Health Affairs, 31(1), 220-227, http://dx.doi.org/10.1377/hlthaff.2011.0762
Nelson, E. C., Batalden, P. B., \& Godfrey, M. M. (2007). Quality by design; a clinical microsystem approach. San Francisco: Jossey-Bass.

Neuhauser, D. (2002). Ernest Amory Codman MD. Quality and Safety in Health Care, 11(1), 104-105, http://dx.doi. org/10.1136/qhc.11.1.104

Nulägesrapport 2014. Satsningen på kvalitetsregister. (Baseline report 2014. The effort of Quality registers). Available at: http://www.kvalitetsregister.se/aktuellt/nu lagesrapport2014.4.409b7ad7144f9a5c5ae8c82d.html (assessed 17 October 2014).

Peterson, A., Carlhed, R., Lindahl, B., Lindström, G., Åberg, C., Andersson-Gäre, B., \& Bojestig, M. (2007). Improving guideline adherence through intensive quality improvement and the use of a National Quality Register in Sweden for acute myocardial infarction. Quality Management in Health Care, 16(1), 25-37, http://dx.doi. org/10.1097/00019514-200701000-00005

Pocha, C. (2010). Lean Six Sigma in Health Care and the Challenge of Implementation of Six Sigma Methodologies at a Veterans Affairs Medical Center. Quality Management in Health Care, 19(4), 312-318, http://dx.doi.org/10.1097/QMH.0b013e3181fa0783

Rosén, H., Sjöberg, H., \& Åström, S. (2010). Översyn av de nationella kvalitetsregistren.Guldgruvan $i$ hälsooch sjukvården: förslag till gemensam satsning 20112015. (Review of national quality registers. The Gold Mine in health care: a proposal forjoint efforts 2011-2015). Available at: http://webbutik.skl.se/sv/ artiklar/guldgruvan-i-halso-och-sjukvarden-forslagtillgemensam-satsning-2011-2015.html/ (accessed 22 April 2013).

Rosengren, K., Höglund, P. J., \& Hedberg, B. (2012). Quality registry, a tool for patient advantages from a preventive caring perspective. Journal of Nursing Management, 20(2), 196-205, http://dx.doi.org/10.1111/j.13652834.2012.01378.x

Saunders, M., Lewis, P., \& Thornhill, A. (2009). Research methods for business students. ( $5^{\text {th }}$ ed. $)$. London: Prentice Hall.

SALAR (2013). Ännu bättre vård. (Even better care). Accessed 22 April 2013 at: http://webbutik.skl.se/sc/ artiklar/annu-battre-vard.html.

S2011/8471/FS. (2011). Överenskommelse mellan Sveriges kommuner och landsting och staten: om utvecklingen och finansieringen av Nationella kvalitetsregister för vaird och omsorg under åren 2012-2016. (Agreement between Sweden's municipalities and county councils and the government: on the development and funding of national quality registers of care during the years 20122016). Accessed 23 May 2013 at: http://www.regeringen. $\mathrm{se} / \mathrm{sb} / \mathrm{d} / 14976 / \mathrm{a} / 177144 /$

SFS 2008:355. (2008). Patientdatalag. (Patient data act). Accessed 22 April 2013 at: 
http://www.riksdagen.se/sv/Dokument-

Lagar/

Svenskforfattningssamlingpatientdatalag-2008355_sfs2008-355/

Waring, J. J., \& Bishop, S. (2010). Lean healthcare: rhetoric, ritual and resistance. Social Science \& Medicine, 71(7), 1332-1340, http://dx.doi.org/10.1016/j. socscimed.2010.06.028

Wong, B. M., Etchells, E. E., Kuper, A., Levinson, W., \& Shojania, K. G. (2010). Teaching quality improvement and patient safety to trainees: a systematic review. Academic Medicine, 85(9), 1425-1439, http://dx.doi. org/10.1097/ACM.0b013e3181e2d0c6

Yin, R. K. (2003). Case study research methods (6 $6^{\text {th }}$ ed.). Fort Worth: Dresden Press.

Annika Nordin is a PhD Candidate at the School of Health Sciences at Jönköping University, Sweden. Her main interest is QI and she works as a project manager of QI at the County Council of Jönköping and in national projects.

Torie Palm Ernsäter is a registered nurse with a master science in nursing, working as a senior adviser at the Swedish Society of Nursing in Stockholm, Sweden. Her main interest is quality improvement, patient safety, teamwork and person-centered care. The Swedish Society of Nursing is the professional society that brings registered nurses together on professional issues. The society constitutes an arena and meeting place for clinical, educational, scientific and ethical discussions and decisions.

Bo Bergman, $\mathrm{PhD}$, is a professor of Quality Sciences at Chalmers University of Technology since 1999 and currently also guest professor at Meiji University. Earlier, he worked for 15 years in the aerospace industry and for 15 years as a professor of Quality Technology at Linköping University. Currently he is very engaged in research for quality improvement in health care. 